\title{
Aislamientos de Staphylococcus aureus sensibles a meticilina relacionados genéticamente con el clon USA300, ¿origen de los aislamientos SARM de genotipo comunitario en Colombia?
}

\author{
Javier Antonio Escobar-Pérez¹, Betsy Esperanza Castro', Ricaurte Alejandro Márquez-Ortiz'1, \\ Sebastián Gaines ${ }^{1}$, Bibiana Chavarro', Jaime Moreno², Aura Lucía Leal ${ }^{3}$, Natasha Vanegas ${ }^{1,4}$ \\ 1 Laboratorio de Genética Molecular Bacteriana, Universidad El Bosque, Bogotá, D.C., Colombia \\ 2 Grupo de Microbiología, Dirección de Investigación en Salud Pública, Subdirección de Investigación Científica y \\ Tecnológica, Instituto Nacional de Salud, Bogotá, D.C., Colombia \\ ${ }^{3}$ Grupo para el Control de la Resistencia Bacteriana en Bogotá, Universidad Nacional de Colombia, Bogotá, D.C., \\ Colombia \\ ${ }^{4}$ I3 Institute, Faculty of Science, University of Technology Sydney, Sydney, Australia \\ Institución donde se realizó el estudio: Universidad El Bosque, Bogotá, D.C., Colombia. \\ Introducción. USA300 es un linaje genético que se encuentra en aislamientos de Staphylococcus \\ aureus sensibles (SASM) y resistentes a meticilina (SARM). Actualmente, en Colombia las infecciones \\ por SARM en hospitales y en la comunidad son causadas principalmente por un clon con genotipo \\ comunitario (SARM-GC) relacionado genéticamente con el clon USA300. El origen de esta variante es \\ aún desconocido. \\ Objetivo. Identificar y caracterizar aislamientos de $S$. aureus resistentes y sensibles a meticilina \\ con el fin de aportar información para establecer un posible origen de los aislamientos SARM-GC \\ en Colombia. \\ Materiales y métodos. Se realizó una caracterización de aislamientos SASM relacionados con el clon \\ USA300 detectados a partir de un análisis de 184 aislamientos de S. aureus (90 SARM y 94 SASM) \\ causantes de infecciones. La relación genética de los aislamientos se determinó por electroforesis en \\ gel de campo pulsado (PFGE), tipificación de secuencias multilocus (MLST) y tipificación del gen de \\ la proteína A (spa). \\ Resultados. De los 184 aislamientos, 27 (14,7\%) presentaron características moleculares y relación \\ genética con el clon USA300, y de ellos, 18 fueron SARM y nueve fueron SASM. Todos los aislamientos \\ SARM relacionados con este clon albergaban un casete estafilocócico cromosómico mec (SCCmec) \\ IVc (3.1.2). En ningún aislamiento SASM se detectaron secuencias remanentes de SCCmec o una \\ duplicación del sitio attB que evidenciaran la pérdida del casete. \\ Conclusión. El origen de los aislamientos SARM-GC en Colombia probablemente se encuentre \\ en la diseminación de clones SASM relacionados con el clon USA300 que adquirieron el SCCmec \\ IVc posteriormente.
}

Palabras clave: Staphylococcus aureus resistente a meticilina, infección, Colombia. doi: http://dx.doi.org/10.7705/biomedica.v34i0.1661

Methicillin-sensitive Staphylococcus aureus isolates related to USA300 clone: Origin of community-genotype MRSA in Colombia?

Introduction: USA300 is a genetic lineage found both in methicillin-resistant (MRSA) and methicillinsensitive Staphylococcus aureus (MSSA) isolates. In Colombia, hospital and community MRSA infections are caused by a USA300-related community genotype MRSA (CG-MRSA) clone. The genetic origin of this clone is unknown yet.

Objective: To identify and characterize methicillin-resistant (MRSA) and methicillin-sensitive $S$. aureus (MSSA) isolates in order to improve the information about the origin of the CG-MRSA isolates in Colombia.

Materials and methods: USA300-related MSSA isolates were detected and characterized from a study of 184 S. aureus isolates (90 MRSA and $94 \mathrm{MSSA}$ ) recovered from infections. The genetic

\section{Contribución de los autores:}

Javier Escobar, Natasha Vanegas, Aura Lucía Leal y Jaime Moreno: diseño de los experimentos.

Javier Escobar, Betsy Castro, Alejandro Márquez, Sebastián Gaines y Bibiana Chavarro: realización de los experimentos y análisis bioinformáticos.

Todos los autores participaron en el análisis de los datos. 
relatedness of the isolates was established by means of pulsed field gel electrophoresis (PFGE), multilocus sequence typing (MLST) and protein A gene typification (spa typing).

Results: Among 184 isolates, 27 (14.7\%) showed molecular characteristics and genetic relationship with the USA300 clone, of which 18 were MRSA and nine were MSSA. All USA300-related MRSA harbored Staphylococcal cassette chromosome mec (SCCmec) IVc (3.1.2). In the MSSA isolates, $\mathrm{SCC}$ mec remnants or attB duplicate sites were not detected.

Conclusions: In Colombia, the CG-MRSA isolates probably originated in the dissemination of an USA300-related MSSA clone which later acquired SCCmec IVc.

Key words: Methicillin-resistant Staphylococcus aureus, infection, Colombia. doi: http://dx.doi.org/10.7705/biomedica.v34i0.1661

Staphylococcus aureus es una bacteria Gram positiva, comensal y patógena de gran importancia clínica, ya que es responsable de una amplia gama de infecciones que incluyen desde infecciones leves de piel y tejidos blandos hasta otras graves como la neumonía, la endocarditis y el choque tóxico. Además, esta bacteria tiene la capacidad de adaptarse rápidamente a presiones selectivas del medio, así como de diseminarse y colonizar a su huésped debido a la amplia variedad de factores de virulencia que expresa (1).

Se denomina con el nombre de Staphylococcus aureus resistente a meticilina (SARM) a los aislamientos de $S$. aureus que han adquirido el gen mecA o mecC, los cuales codifican las proteínas de unión a penicilina 2a (PBP2a), confiriéndole al microorganismo resistencia a la mayoría de antibióticos betalactámicos. Estos genes son transportados por el casete estafilocócico cromosómico mec (Staphylococcal Cassette Chromosome $\mathrm{mec}, \mathrm{SCC} m e c)$, un elemento genético móvil que se inserta en un sitio específico del cromosoma bacteriano denominado attB, y está inmerso en un marco abierto de lectura (Open Reading Frame, ORF) altamente conservado denominado orfX (2). Por otro lado, los aislamientos que son sensibles a la oxacilina (la mayoría de antibióticos betalactámicos) son conocidos como $S$. aureus sensibles a meticilina (SASM). Aunque el primer aislamiento SARM fue detectado hace más de 50 años, aproximadamente la mitad de las infecciones hospitalarias por $S$. aureus son causadas por aislamientos SASM, lo cual sugiere que estos últimos, a pesar de no tener SCCmec, deben tener ventajas genéticas que favorecen su diseminación.

\footnotetext{
Correspondencia:

Javier Antonio Escobar-Pérez, Universidad El Bosque, Carrera 7B bis № 132-11, Edificio Rectoría, segundo piso, Bogotá, D.C., Colombia

Teléfono: 523 4879, 633 1368, extensión: 179; fax: 6252030

javiesco21@yahoo.com, labgenmolecular@unbosque.edu.co

Recibido: 05/06/13; aceptado: 22/11/13
}

EI USA300 es un clon SARM detectado en el año 2000 en Estados Unidos que causa principalmente infecciones de piel y tejidos blandos y neumonías complicadas en personas de la comunidad (3). Actualmente, este clon se ha diseminado a varios continentes (4-7). EI USA300 tiene las siguientes características moleculares: un tipo de secuencia 8 (ST8), tipo de spa t008, SCCmec IVa, grupo de agr 1, y posee los genes lukS-PV/lukF-PV, sek, seq, bsaB y sak, que codifican para la leucocidina Panton Valentine (PVL), la enterotoxina $Q$, la enterotoxina $\mathrm{K}$, la bacteriocina y la estafilocinasa, respectivamente. En este clon, además, se identificó por primera vez el elemento móvil para el catabolismo de la arginina (Arginine Catabolic Mobile Element, ACME), el cual se ha propuesto como un elemento que aumenta la capacidad de la bacteria de sobrevivir en ambientes ácidos y en anaerobiosis (3).

En Colombia y en varios países de Suramérica se ha reportado la diseminación de aislamientos SARM asociados a la comunidad (SARM-AC), los cuales causan infecciones no solo en personas en la comunidad, sino también en pacientes hospitalizados (8-11). La mayoría de estos aislamientos presentan características moleculares similares al clon USA300 diseminado en Estados Unidos: la ST8 y los genes lukS-PV/lukF-PV, seq, sek y bsa (8-10). Sin embargo, estos aislamientos no poseen el elemento ACME, presentan un patrón de restricción genómico con la enzima Smal diferente (cuatro bandas de diferencia) y un SCCmec diferente de IVc (8-10). El origen de esta variante del clon USA300 aún se desconoce.

Para entender la dinámica de poblaciones, el origen y la posible evolución de los aislamientos SARMGC en Colombia, en este trabajo analizamos las características microbiológicas, genéticas y moleculares de aislamientos SASM relacionados con el clon USA300 recuperados durante el año 2007, poco después de los primeros reportes de SARM-GC en Colombia, ya que la primera infección 
por este tipo de aislamientos en nuestro país se reportó en diciembre de 2006. Los resultados encontrados permiten sugerir que el posible origen de los aislamientos SARM-GC en Colombia se encuentra en la diseminación de un clon SASM relacionado con el clon USA300 que adquirió un $\mathrm{SCC} m e c \mathrm{IVc}$ (3.1.2).

\section{Materiales y métodos}

\section{Aislamientos bacterianos}

Se analizaron 184 aislamientos de $S$. aureus recolectados de manera prospectiva y secuencial a partir de infecciones invasivas de pacientes adultos (18 a 65 años) atendidos entre enero y diciembre de 2007 en un hospital de cuarto nivel de Bogotá, y que fueron almacenados en el Laboratorio de Genética Molecular Bacteriana de la Universidad El Bosque (se seleccionó un aislamiento por paciente).

\section{Confirmación de especie y sensibilidad de los aislamientos a 11 tipos de antibióticos}

La especie y la resistencia a meticilina de los aislamientos se confirmó por la amplificación de los genes nuc y mecA de acuerdo con las condiciones descritas previamente (12). La concentración inhibitoria mínima (CIM) de los aislamientos frente a oxacilina, gentamicina, vancomicina, ciprofloxacina, eritromicina, clindamicina, rifampicina, cloranfenicol, trimetroprim-sulfametoxazol, tetraciclina y linezolid se determinó por medio del método de dilución en agar siguiendo los parámetros establecidos por el Clinical and Laboratory Standards Institute, 2013 (13). La cepa de S. aureus ATCC 29213 se utilizó como control.

\section{Determinación del tipo SCCmec, el tipo de spa y el grupo de agr}

El tipo y subtipo de $\mathrm{SCCmec}$ de los aislamientos SARM se estableció según lo reportado previamente $(14,15)$. En los aislamientos con un SCCmec IVc o IVE el subtipo se confirmó por medio de la amplificación de fragmentos específicos de la región J3 utilizando los iniciadores GP183 a GP180 (cuadro 1) $(12,16,17)$. Las condiciones de amplificación fueron las siguientes: $94^{\circ} \mathrm{C}$ por cuatro minutos; 30 ciclos de $94^{\circ} \mathrm{C}$ por 30 segundos, $48^{\circ} \mathrm{C}$ por 30 segundos y $72{ }^{\circ} \mathrm{C}$ por un minuto, y una extensión final a $72{ }^{\circ} \mathrm{C}$ por siete minutos.

Para la amplificación diferencial de las regiones J3 de los subtipos IVc (IV.3.1.2) y IVa (IV.1.1.1) se utilizaron los iniciadores GP334 a GP339 en las siguientes condiciones: $94{ }^{\circ} \mathrm{C}$ por cinco minutos; 30 ciclos de $94{ }^{\circ} \mathrm{C}$ por un minuto, $47^{\circ} \mathrm{C}$ por un minuto, $72{ }^{\circ} \mathrm{C}$ por 10 minutos, y una extensión final a $72{ }^{\circ} \mathrm{C}$ por 20 minutos.

Las cepas USA300 (IVa, IV.1.1.1), 81/108 (IVc, IV.3.1.1), AR543 (IVc, IV.3.1.2) y AS7654 (IVE, IV.3.1.4) se utilizaron como control y fueron proporcionadas por Keiichi Hiramatsu y Teruyo Ito de la Universidad de Jutendo, Japón.

Cuadro 1. Principales iniciadores utilizados para la caracterización de la región J3 del SCCmec IV.3.1.1 (IVc), IV.3.1.1 (IVc), IV.1.1.1 (IVa) y IV.3.1.4 (IVE)

\begin{tabular}{|c|c|c|c|c|c|c|}
\hline \multicolumn{2}{|c|}{ Iniciador } & \multirow[t]{2}{*}{ Secuencia } & \multirow[t]{2}{*}{ Posición ${ }^{a}$} & \multirow{2}{*}{$\begin{array}{c}\text { Tamaño } \\
(\mathrm{pb})\end{array}$} & \multirow[t]{2}{*}{ Especificaciones } & \multirow[t]{2}{*}{ Referencia } \\
\hline Código & Nombre & & & & & \\
\hline $\begin{array}{l}\text { GP183 } \\
\text { GP184 }\end{array}$ & $\begin{array}{l}\mathrm{J} I V_{c} F \\
\mathrm{~J} I V_{c} R\end{array}$ & $\begin{array}{l}\text { CCATTGCAAATTTCTCTTCC } \\
\text { ATAGATTCTACTGCAAGTCC }\end{array}$ & $14.713-14.230$ & 483 & $\begin{array}{l}\text { Región J1 de IVc (IV.3.1.1), } \\
\text { IVc (IV.3.1.2) y IVE (IV.3.1.4) } \\
\text { (control interno) }\end{array}$ & $\begin{array}{l}(16) \\
(16)\end{array}$ \\
\hline $\begin{array}{l}\text { GP175 } \\
\text { GP176 }\end{array}$ & $\begin{array}{l}\text { IVc-1 F } \\
\text { IVc-1 R }\end{array}$ & $\begin{array}{l}\text { TCCCAACCCCTTTATTTTTGA } \\
\text { CCATTTCGTTGACTTTGTCG }\end{array}$ & $3.567-3.967$ & 400 & $\begin{array}{l}\text { Iniciador específico para la } \\
\text { región J3 de IVc (IV.3.1.1) }\end{array}$ & $\begin{array}{l}\text { Este estudic } \\
\text { Este estudic }\end{array}$ \\
\hline $\begin{array}{l}\text { GP177 } \\
\text { GP178 }\end{array}$ & $\begin{array}{l}\text { IVc-2 F } \\
\text { IVc-2 R }\end{array}$ & $\begin{array}{l}\text { TCAATTTCGCTGTCTTCCTG } \\
\text { ATGCTGCAAAACAAAGAGCA }\end{array}$ & $4.395-4.718$ & 325 & $\begin{array}{l}\text { Iniciador para la región J3 de } \\
\text { IVc (IV.3.1.2) y IVa (IV.1.1.1) }\end{array}$ & $\begin{array}{l}\text { Este estudic } \\
\text { Este estudic }\end{array}$ \\
\hline $\begin{array}{l}\text { GP179 } \\
\text { GP180 }\end{array}$ & $\begin{array}{l}\text { IVE-4 F } \\
\text { IVE-4 R }\end{array}$ & $\begin{array}{l}\text { CGCTGACTTAGAAGGGCAAG } \\
\text { CCGTAATTGCAGCATTTTGA }\end{array}$ & $5.910-6.160$ & 251 & $\begin{array}{l}\text { Iniciador específico para la } \\
\text { región J3 de IVE (IV.3.1.4) }\end{array}$ & $\begin{array}{l}\text { Este estudic } \\
\text { Este estudic }\end{array}$ \\
\hline $\begin{array}{l}\text { GP334 } \\
\text { GP164 }\end{array}$ & $\begin{array}{l}\text { mecAlong } \\
\text { orfx }\end{array}$ & $\begin{array}{l}\text { ATGAGCTATATGAGAACGGT } \\
\text { GGATCAAACGGCCTGCACA }\end{array}$ & $(-) 46-5.092$ & 5138 & genes mecA y orf $X$ & $\begin{array}{l}\text { Este estudic } \\
\quad(17)\end{array}$ \\
\hline $\begin{array}{l}\text { GP171 } \\
\text { GP172 }\end{array}$ & $\begin{array}{l}\text { mecA-S } \\
\text { mecA-AS }\end{array}$ & $\begin{array}{l}\text { ATTGCTGTTAATATTTTTTTGAGTTGAA } \\
\text { CTTACAAGTGCTAATAATTCACCTGTT }\end{array}$ & $948-775$ & 174 & gen $m e c A$ & $\begin{array}{l}(12) \\
(12)\end{array}$ \\
\hline $\begin{array}{l}\text { GP338 } \\
\text { GP339 }\end{array}$ & $\begin{array}{l}\text { NestedJ3-1 } \\
\text { NestedJ3-2 }\end{array}$ & $\begin{array}{l}\text { CAAGGATGTTATCACTGTAG } \\
\text { TTATATCGTGCCATTGATGC }\end{array}$ & $\mathrm{PV}^{\mathrm{b}}$ & $\mathrm{TV}^{\mathrm{c}}$ & $\begin{array}{l}\text { Iniciadores sentido para el } \\
\text { gen tnp de la región J3 de } \\
\text { IVc (IV.3.1.2) y IVa (IV.1.1.1) }\end{array}$ & $\begin{array}{l}\text { Este estudic } \\
\text { Este estudic }\end{array}$ \\
\hline
\end{tabular}

a. Teniendo como referencia el inicio de la región J3 del SCCmec, a excepción de los iniciadores GP183 y GP184, que tienen como referencia el inicio del SCCmec.

b. Posición variable

c. Tamaño variable 
El tipo de spa se determinó utilizando las condiciones descritas por Harmsen, et al. (18), pero con los iniciadores GGATCAAACGGCCTGCACA y TAAACCAATTTGATAGGGCC, y la clasificación se realizó de acuerdo con los criterios sugeridos por el Ridom SpaServer (http://spaserver.ridom.de). El grupo de agr se determinó según la metodología reportada por Gilot, et al. (19).

\section{Determinación de la posible escisión del ScCmec}

La posible escisión del SCCmec en los aislamientos SASM se determinó por medio de la búsqueda de fragmentos residuales de este casete utilizando el ensayo IDI-SARM (20) y por la amplificación y secuenciación del sitio attB y sus alrededores con los iniciadores y en las condiciones descritas previamente (17). Debido a la variabilidad genética encontrada después del marco orf $X$, con esta última metodología también se utilizaron los iniciadores TAAACCAATTTGATAGGGCC y CCTCCCACAATTTACCACCTC, localizados corriente abajo del sitio attB.

\section{Detección de genes para factores de virulencia y ACME}

Los genes lukF-PV y lukS-PV, seq, sek, sem, seo, bsaB y sak se detectaron por medio de PCR. Los aislamientos positivos para PVL se confirmaron por medio de la PCR descrita por Lina, et al. (21). La localización de los genes seq y sek dentro de la isla de capacidad patógena 5 fue confirmada por PCR utilizando un iniciador específico de seq o sek y el iniciador AYGGTGCAGTTATTCCTG, localizado corriente arriba del sitio de inserción de esta isla en el genoma de $S$. aureus. La presencia de la isla de capacidad patógena 5 se confirmó por medio de la amplificación del gen sausa300_0808 utilizando los iniciadores TAATCATGGCTCGCATTTTG y GCGTTATCTTGGCTTTGGTC. El elemento ACME se determinó por medio de la amplificación de los genes arcC y opp utilizando las parejas de iniciadores específicos GGTTTAAATTATGCGGCGGA, AACTAGTGTTCCATGAGTGAT y GCAAATCTGTA AATGGTCTGTTC, GCTGACGTTGCACTTTTTCA, respectivamente, diseñados en este estudio. Las cepas USA300-0114, N315 y Mu50 se utilizaron como control en estos ensayos.

\section{Determinación de la relación genética}

La relación genética de los aislamientos se determinó por medio de restricción genómica con la enzima Smal y posterior separación por electroforesis en gel de campo pulsado (Pulsed
Field Gel Electrophoresis, PFGE) de acuerdo con las condiciones descritas por Chung, et al. (22). Los resultados de PFGE se analizaron utilizando el software GelCompar II ${ }^{\mathrm{TM}}$ (Biorad), con el coeficiente Dice y una tolerancia de 1,5\%. La interpretación de la relación genética de los pulsotipos encontrados se realizó de acuerdo con los criterios sugeridos por Tenover, et al. (23). El tipo de secuencia se estableció según la metodología descrita por Enright, et al., (24) y el polimorfismo de los genes arcC y gmk de acuerdo con las condiciones reportadas previamente (25).

\section{Resultados}

\section{Relación genética de los aislamientos}

De los 184 aislamientos de $S$. aureus analizados, $90(48,9 \%)$ fueron SARM y 94 (51,1\%), SASM. En el cuadro 2 se presenta una comparación de las características encontradas en estos dos tipos de aislamientos.

Según el patrón de bandas obtenido por PFGE, de los 90 aislamientos SARM analizados, 68 (75,6 \%) se relacionaron con el clon chileno (patrón F), 39 $(43,3 \%)$ de estos aislamientos con pulsotipos indistinguibles y 29 (32,2 \%) aislamientos con pulsotipos estrechamente relacionados ( $<3$ bandas de diferencia), 18 (20,0\%) aislamientos presentaron ocho pulsotipos diferentes que estuvieron relacionados con el clon USA300 (patrón U) $(<6$ bandas de diferencia), dos (2,2\%) aislamientos presentaron un pulsotipo indistinguible respecto al clon pediátrico (patrón D) y dos (2,2\%) aislamientos presentaron pulsotipos no relacionados con los clones chileno, pediátrico y USA300 (figura 1).

Entre los 94 aislamientos SASM se encontraron 70 pulsotipos diferentes y se organizaron en 21 grupos genómicos (figura 1). El 54,2\% de los aislamientos SASM $(n=51)$ se clasificaron en cuatro grupos genómicos E, B, H y U con 21 (23,3 \%), 11 (12,2\%), $10(11,1 \%)$ y nueve $(10,0 \%)$ aislamientos, respectivamente. Los nueve aislamientos que conforman el grupo $U$ se relacionaron con el clon USA300 y solo se encontró un aislamiento SASM asociado con el clon chileno (F) (figura 1). Estos resultados muestran una mayor variabilidad genética de los aislamientos SASM comparada con el comportamiento 'clonal' de los aislamientos SARM como se ha reportado en otros estudios a nivel mundial (26-28).

Los 68 aislamientos SARM relacionados genéticamente con el clon chileno presentaron un SCCmec de tipo I, eran multirresistentes, con 
Cuadro 2. Comparación de las principales características encontradas en todos los aislamientos y las encontradas en los aislamientos relacionados con el clon USA300. Los valores más altos se resaltan en negrilla.

\begin{tabular}{|c|c|c|c|c|c|}
\hline \multirow[t]{2}{*}{ Característica } & \multicolumn{2}{|c|}{ Todos los aislamientos $(n=184)$} & \multicolumn{3}{|c|}{ Aislamientos relacionados con USA300 $(n=27)$} \\
\hline & SASM $(n=94)$ & SARM $(n=90)$ & SASM $(n=9)$ & SAR & $M(n=18)$ \\
\hline Fuente & n (\%) & n (\%) & n (\%) & & n (\%) \\
\hline Sangre & $34(36,1)$ & $54(60,0)$ & $2(22,2)$ & 7 & $(38,9)$ \\
\hline Secreción de herida quirúrgica & $18(19,2)$ & $22(24,4)$ & $2(22,2)$ & 5 & $(27,8)$ \\
\hline Secreción de piel y tejidos blandos & $10(10,6)$ & $6(6,6)$ & $4(44,4)$ & 6 & $(33,3)$ \\
\hline Orina & $4(4,2)$ & $2(2,2)$ & $1(11,1)$ & 0 & $(0,0)$ \\
\hline Líquido cefalorraquídeo & $0 \quad(0,0)$ & $1 \quad(1,1)$ & $0 \quad(0,0)$ & 0 & $(0,0)$ \\
\hline Secreciones broncoalveolares & $9(9,5)$ & $0(0,0)$ & $0 \quad(0,0)$ & 0 & $(0,0)$ \\
\hline Otros & $19(20,1)$ & $5 \quad(5,5)$ & $0 \quad(0,0)$ & 0 & $(0,0)$ \\
\hline \multicolumn{6}{|l|}{ Resistencia } \\
\hline Ciprofloxacina & $3(3,2)$ & $74(82,2)$ & $1(11,1)$ & 2 & $(11,1)$ \\
\hline Clindamicina & $2(2,1)$ & $71(78,8)$ & $1(11,1)$ & 2 & $(11,1)$ \\
\hline Eritromicina & $10(10,6)$ & $70(77,7)$ & $2(22,2)$ & 2 & $(11,1)$ \\
\hline Gentamicina & $1(1,1)$ & $45(50,0)$ & $0 \quad(0,0)$ & 0 & $(0,0)$ \\
\hline Tetraciclina & $9(9,6)$ & $13(14,4)$ & $0 \quad(0,0)$ & 9 & $(50,0)$ \\
\hline Rifampicina & $0 \quad(0,0)$ & $6(6,7)$ & $0 \quad(0,0)$ & 0 & $(0,0)$ \\
\hline Cloranfenicol & $0(0,0)$ & $5 \quad(5,5)$ & $0 \quad(0,0)$ & 1 & $(5,5)$ \\
\hline \multicolumn{6}{|l|}{ Corresistencia } \\
\hline Ninguno & $74(78,7)$ & $0(0,0)$ & $6(66,6)$ & 0 & $(0,0)$ \\
\hline 1 antibiótico & $16(17,0)$ & $6(6,6)$ & $2(22,2)$ & 6 & $(33,3)$ \\
\hline 2 antibióticos & $2(2,1)$ & $10(11,6)$ & $1 \quad(11,1)$ & 9 & $(50,0)$ \\
\hline 3 antibióticos & $2(2,1)$ & $3(3,3)$ & $0 \quad(0,0)$ & 2 & $(11,1)$ \\
\hline 4 antibióticos & $0 \quad(0,0)$ & $22(24,4)$ & $0 \quad(0,0)$ & 1 & $(5,5)$ \\
\hline 5 antibióticos & $0(0,0)$ & $43(47,7)$ & $0 \quad(0,0)$ & 0 & $(0,0)$ \\
\hline$>5$ antibióticos & $0 \quad(0,0)$ & $6(6,6)$ & $\begin{array}{ll}0 & (0,0)\end{array}$ & 0 & $(0,0)$ \\
\hline \multicolumn{6}{|l|}{ Factores de virulencia } \\
\hline seo, sem & $63(67,0)$ & $72(80,0)$ & $0 \quad(0,0)$ & 0 & $(0,0)$ \\
\hline bsaB & $19(20,1)$ & $18(19,2)$ & $9(100)$ & 18 & $(100)$ \\
\hline seq & $13(13,8)$ & $17(18,8)$ & $4(44,4)$ & 17 & $(94,4)$ \\
\hline sek & $13(13,8)$ & $16(17,7)$ & $4 \quad(44,4)$ & 16 & $(88,9)$ \\
\hline lukF-PV/lukS-PV (PVL) & $6(6,4)$ & $17(18,8)$ & $3(33,3)$ & 17 & $(94,4)$ \\
\hline
\end{tabular}

predominio de la resistencia múltiple a aminoglucósidos, fluoroquinolonas, macrólidos y lincosamidas, y contenían los genes seo y sem. Algunos estudios previos han asociado estas características moleculares al clon mencionado (29-31). Los dos aislamientos idénticos al clon pediátrico contenían un SCCmec de tipo IV y los dos aislamientos que presentaron los pulsotipos no relacionados tenían un $\mathrm{SCC} m e c$ de tipo II; estos aislamientos contenían los genes seo y sem y fueron multirresistentes.

Fuente y perfil de sensibilidad de aislamientos relacionados con el clon USA300

La mayoría de los aislamientos SARM relacionados con USA300 (SARM-USA300) se recuperó de muestras de sangre (siete de 18 aislamientos), con un comportamiento similar al resto de aislamientos SARM (cuadro 2). Este resultado sugiere que en el año 2007 los aislamientos SARM-USA300 ya estaban causando infecciones en pacientes en Colombia, como fue informado previamente por nuestro grupo (10). Por el contrario, la mayoría de los aislamientos SASM relacionados con USA300 (SASM-USA300) se recuperaron de pacientes con infecciones de piel y tejidos blandos (cuatro de nueve aislamientos) (cuadro 2). En términos de resistencia, la mayoría de los aislamientos SASM-USA300 no presentó resistencia a ninguno de los antibióticos evaluados (seis aislamientos), mientras que la mitad de los aislamientos SARMUSA300 presentó resistencia a dos antibióticos (seis aislamientos), predominando la resistencia a tetraciclina. Ninguno de los aislamientos SARM o SASM fue resistente a trimetroprim-sulfametoxazol, linezolid ni vancomicina.

Establecimiento del SCCmec y análisis de la región J3 de los aislamientos SARM relacionados con USA300

De los 90 aislamientos SARM analizados, 18 (20,0\%) presentaron un SCCmec IVc y correspondieron a SARM-USA300. Actualmente, se han reportado dos secuencias diferentes de SCCmec IVc, denominadas IV.3.1.1 y IV.3.1.2 de acuerdo con la nomenclatura propuesta por el International Working Group on the Staphylococcal Cassette Chromosome Elements (IWG-SCC) (32), las cuales no pueden ser diferenciadas utilizando la metodología propuesta por Milheirico, et al. (16). 
PFGE

A

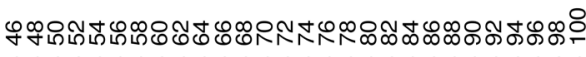
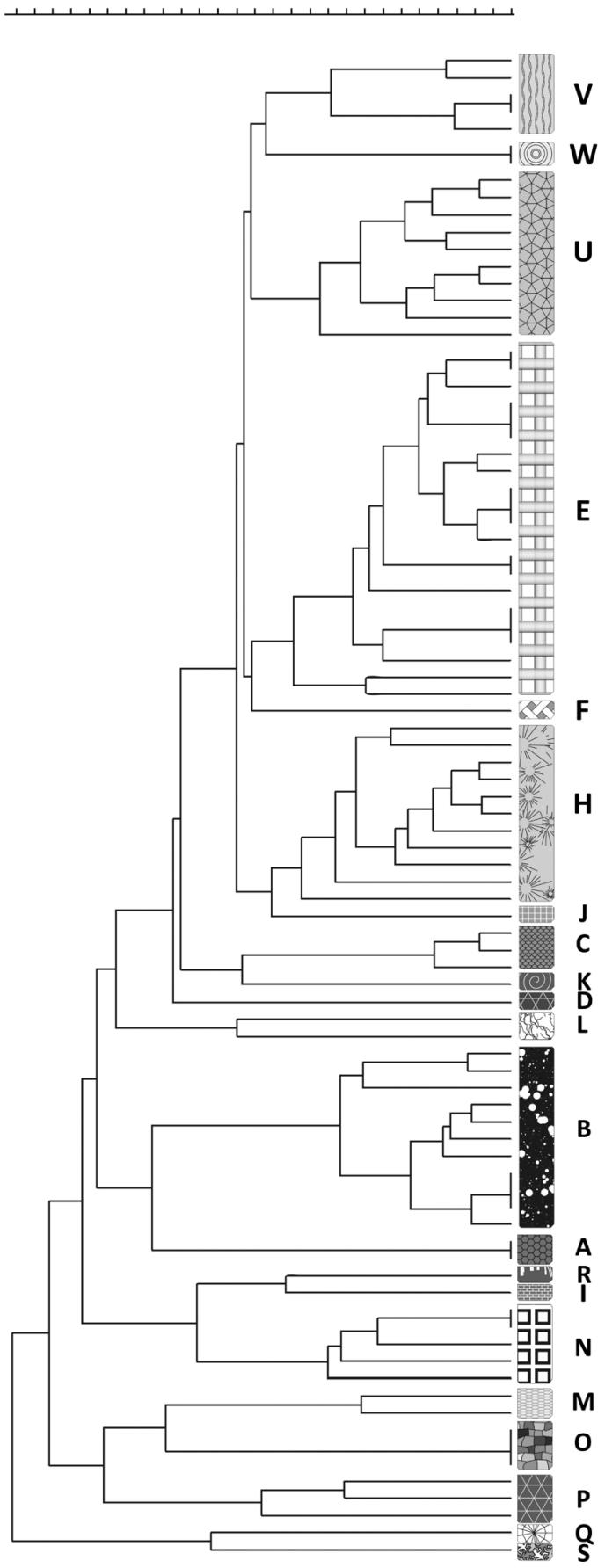

PFGE Clon

B

นึก 8 ๖

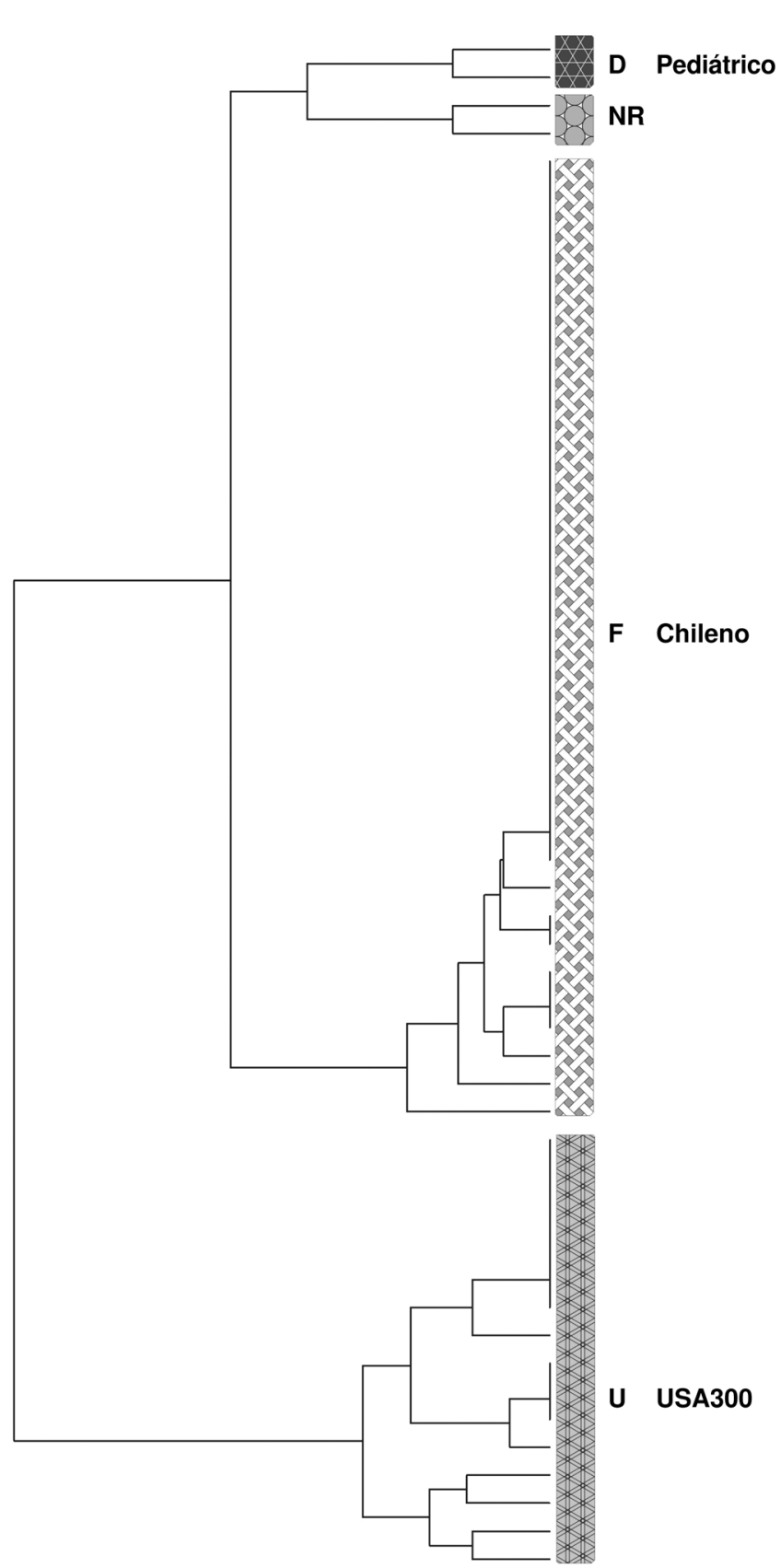

Figura 1. Dendrograma y subgrupos genéticos obtenidos de los aislamientos SASM y SARM analizados. Los subgrupos se conformaron con aislamientos con más de $80 \%$ de relación genética con respecto a los pulsotipos de PFGE obtenidos. A. Aislamientos SASM. B. Aislamientos SARM. Las letras indican los diferentes subgrupos encontrados en los dos tipos de aislamientos.

F: clon chileno; U: clon USA300; D: clon pediátrico; NR: no relacionado con estos tres clones 
El determinar la secuencia a la cual corresponden los aislamientos SARM-USA300 es importante para establecer la relación epidemiológica con otros aislamientos, ya que se han reportado SARM con SCCmec IVc en otros países suramericanos, pero no se sabe si pertenecen al subgrupo IV.3.1.1 o al IV.3.1.2 (33). Un análisis detallado de la región J3 de estos dos tipos de SCCmec muestra cambios en su estructura genómica debidos a la inserción diferencial de secuencias o elementos genéticos móviles como el transposón Tn4001 en el SCCmec IV.3.1.1, o a la deleción de fragmentos de ADN (figura 2A). Todos los aislamientos SARM con SCCmec IVc amplificaron únicamente el fragmento correspondiente al tipo de SCCmec IVc (IV.3.1.2) (no se presentan los resultados).

Un alineamiento de las secuencias de las regiones J3 del SCCmec IVc (IV.3.1.2) y IVa (IV.1.1.1) reportadas por el IWG-SCC (30) muestra un alto porcentaje de identidad (95\%) y tamaños muy similares, $5.392 \mathrm{pb}$ y $4.937 \mathrm{pb}$, respectivamente. El SCCmec IVc (IV.3.1.2) tiene dos deleciones de $80 \mathrm{pb}$ y $40 \mathrm{pb}$, en las posiciones 1.683 y 1.803 , respectivamente, y una inserción de 604 pb en la posición 3.309 respecto al SCCmec IVa (IV.1.1.1).

En la figura $2 \mathrm{~A}$ se muestra un esquema comparativo de la organización genómica de la región J3 de los tipos de SCCmec IVc (IV.3.1.1), IVc (IV.3.1.2), IVE (IV.3.1.4) y IVa, IV.1.1.1, la localización de los iniciadores utilizados para su tipificación y los diferentes productos de amplificación obtenidos para dos aislamientos SARM-USA300 colombianos $y$ el clon USA300 al utilizar las diferentes combinaciones de iniciadores. Los iniciadores GP334 y GP177 amplificaron un producto de, aproximadamente, $4.300 \mathrm{pb}$ y $4.700 \mathrm{pb}$ en el clon USA300 y los aislamientos clínicos SARM, respectivamente (figura $2 B$, sección $A$ ).

En el clon USA300, los iniciadores GP338-GP177 y GP339-GP177, localizados alrededor de la inserción de 576 pb en el SCCmec IVc (IV.3.1.2), amplificaron dos productos de, aproximadamente, $1.600 \mathrm{pb}$ y $2.200 \mathrm{pb}$, respectivamente. Estos productos fueron de menor tamaño comparado con los obtenidos para los dos aislamientos clínicos SARM de 2.200 pb y 2.800 pb (figura 1B, sección $B$ y D). Para confirmar que las diferencias de tamaños de los productos de amplificación se debieron a la existencia de esta inserción en el SCCmec IVc (IV.3.1.2), se diseñó un iniciador específico en esta región (GP176) que al ser utilizado con el iniciador GP177 amplificó un producto de, aproximadamente, $1.300 \mathrm{pb}$ en los dos aislamientos clínicos SARM, pero no en el clon USA300 (figura 1B, sección E). Estos resultados confirman que el SCCmec IVc (IV.3.1.2) tiene una inserción de ADN de aproximadamente 600 pb.

Finalmente, al emplearse los iniciadores GP178 y orf $X$, se obtuvo un producto de, aproximadamente, $1.150 \mathrm{pb}$ tanto para el clon USA300 como para los aislamientos clínicos (figura 2, sección C), lo cual sugiere que los dos tipos de aislamientos tienen la misma región final del SCCmec. A partir de estos resultados se puede confirmar que los aislamientos SARM-GC diseminados en Colombia tienen un SCCmec tipo IVc (IV.3.1.2).

\section{Caracterización molecular de los aislamientos relacionados con el clon USA300}

Los aislamientos SASM-USA300 presentaron una mayor variabilidad genética que los aislamientos SARM-USA300, ya que se encontraron siete pulsotipos (figura 3). Aunque los genes seo y sem se encontraron con mucha frecuencia en los aislamientos SARM y SASM, estos no se detectaron en los aislamientos sensibles y resistentes a meticilina relacionados con el clon USA300 (cuadro 2). Estos genes generalmente se encuentran contenidos en el grupo de enterotoxinas egc, el cual a su vez es trasportado frecuentemente en la isla genómica $\beta$ tipo I (34). Por el contrario, el gen $b s a B$ se detectó en todos los aislamientos relacionados con el clon USA300; este gen también es transportado en la isla genómica $\beta$, pero en la de tipo II, que es el mismo tipo encontrado en el clon USA300 (3). Los genes seq y sek se detectaron en $17(18,8 \%)$ y $16(17,7 \%)$ aislamientos SARM y todos correspondían a SARM-USA300. Con respecto a los SASM, los genes seq y sek se encontraron en $13(13,8 \%)$ aislamientos, pero solo cuatro de estos aislamientos fueron relacionados con el clon USA300 (cuadro 2). Los análisis de PCR (Materiales y métodos) demostraron que estos dos genes son transportados en la isla de capacidad patógena 5 en los aislamientos SARM y SASM. Los genes lukF-PV/lukS-PV fueron detectados en $17(94,4 \%)$ aislamientos SARM-USA300 y en tres $(33,3 \%)$ aislamientos SASM-USA300 (figura 3).

Todos los aislamientos SARM-USA300 y SASMUSA300 pertenecían al grupo de agr I y tenían las variaciones de nucleótidos en los genes arcC y gmk presentes en la ST8 (CC8). Tres aislamientos SARM-USA300 y cinco SASM-USA300, representativos de los principales pulsotipos 
A.
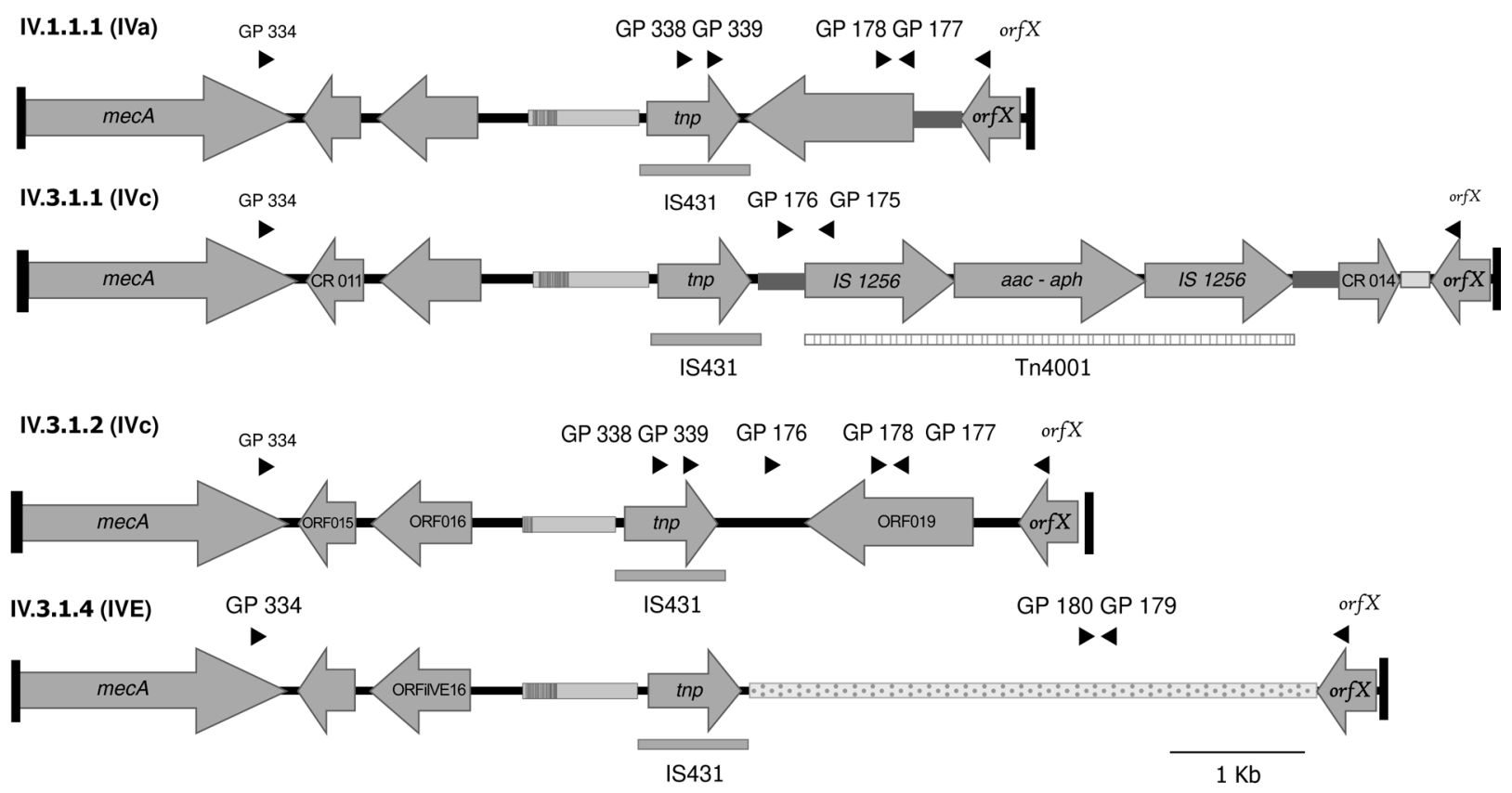

B.

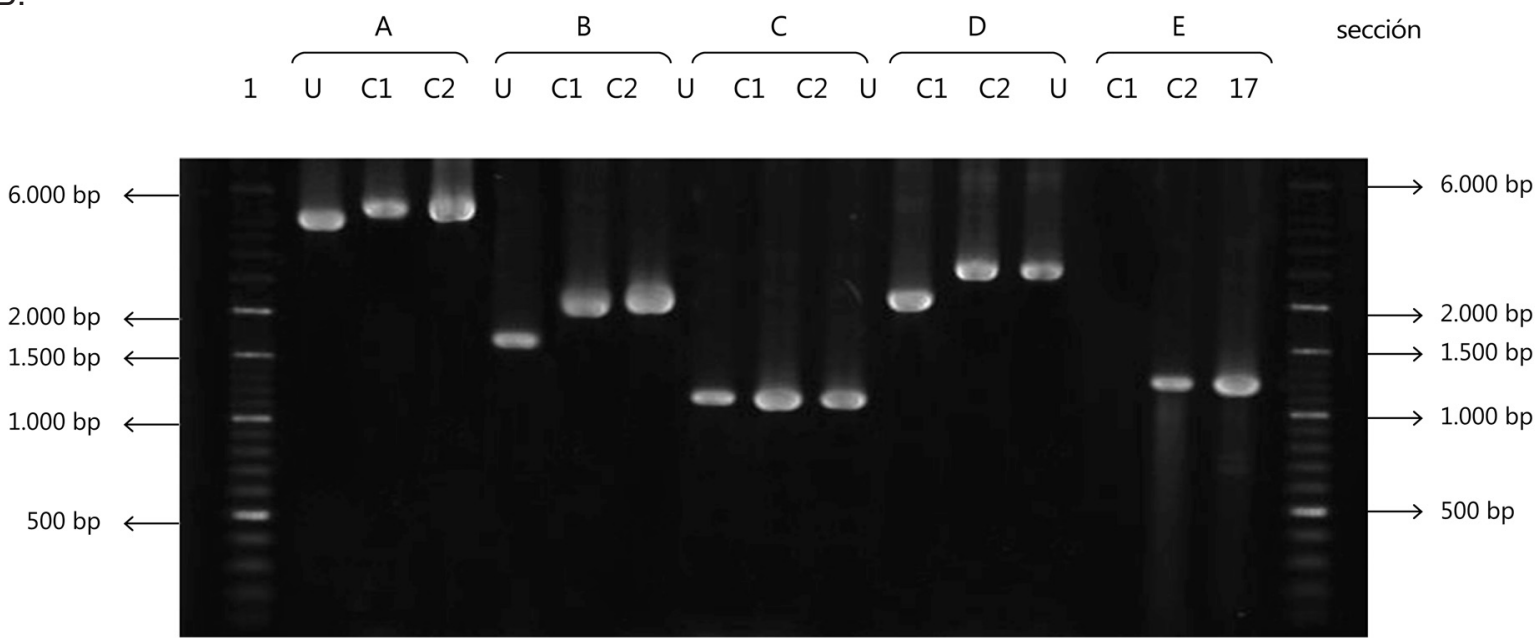

Figura 2. A. Esquema de la organización genética de las regiones J3 reportadas para los tipos de SCCmec IVc (IV.3.1.1), IVc (IV.3.1.2), IVE (IV.3.1.4) y IVa (IV.1.1.1). Los triángulos negros representan la localización de los iniciadores utilizados para su identificación y diferenciación. B. Fragmentos de ADN amplificados de la región J3 de los tipos de SCCmec IVc (IV.3.1.2) y IVa (IV.1.1.1) por medio de PCR utilizando las diferentes combinaciones de los iniciadores diseñados (cuadro 1).

Carriles 1 y 17: marcadores de peso molecular de 500 pb (Fermentas ${ }^{\circledR}$ ). U: clon USA300, C1: aislamiento clínico MRSA 1 (Col 503), C2: aislamiento clínico MRSA 2 (Col 65). Sección A: iniciadores GP334 y GP177, fragmentos esperados para U = 4308 pb y para $\mathrm{C} 1$ y C2 $=4.764$ pb. Sección B: iniciadores GP338 y GP177, fragmentos esperados para $U=1.658$ pb y para C1 y C2 = 2.234 pb. Sección C: iniciadores GP178 y orfX, fragmentos esperados para U $=1.154$ pb y para C1 y C2 $=1.154$ pb. Sección D: iniciadores GP339 y orfX, fragmentos esperados para $U=2.252$ pb y para C1 y C2 $=2.828$ pb. Sección E: iniciadores GP176 y GP177, fragmentos esperados para $U=$ ninguno y para $\mathrm{C} 1$ y $\mathrm{C} 2=1.314 \mathrm{pb}$ 


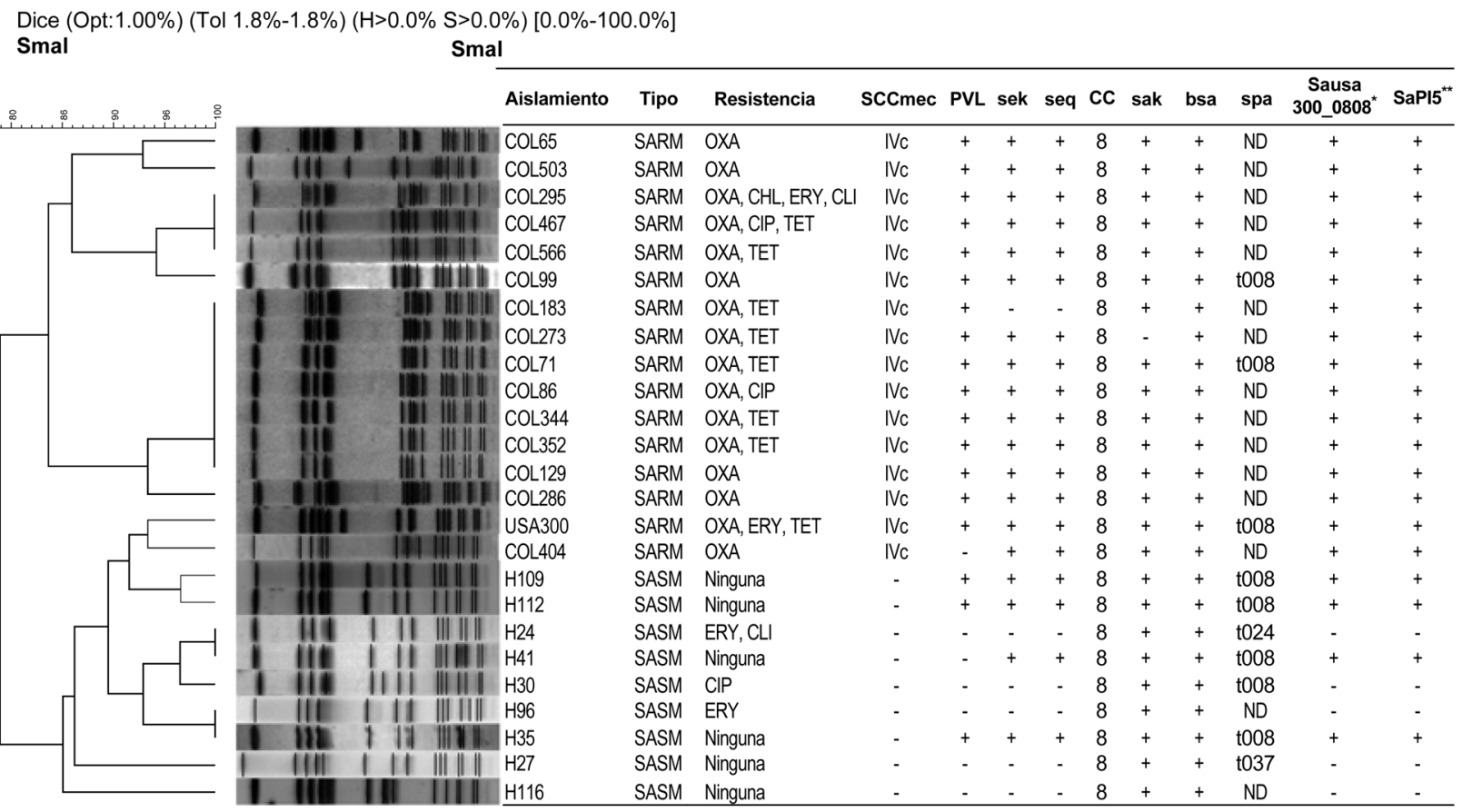

Figura 3. Relación genética y características microbiológicas y moleculares de los aislamientos SASM y SARM. El dendrograma muestra la relación genética de los aislamientos con respecto al clon USA300-0114.

SARM: S. aureus resistente a meticilina; SASM: $S$. aureus sensible a meticilina

Resistencia antimicrobiana: OXA: oxacilina, CHL: cloranfenicol, ERY: eritromicina, CLI: clindamicina, CIP: ciprofloxacina, TET: tetraciclina Presencia de genes que codifican diferentes factores de virulencia: PVL: leucocidina Panton Valentine; sek, enterotoxina K; seq, enterotoxina Q. CC: complejo 'clonal'. sak: estafilocinasa. bsa: bacteriocina; spa: tipo de proteína A. SaPI5: isla de capacidad patógena 5; ND: no determinado.

* Gen específico de SaPI5, ** SaIP5: isla de capacidad patógena 5

encontrados en cada grupo, presentaron el tipo de spa t008, idéntico al encontrado en el clon USA300. Además, dos aislamientos SASM-USA300 poseían el tipo de spa t024 (relacionado con el t008 del USA300). Se seleccionaron dos aislamientos para MLST que presentaron un tipo de secuencia 8 (ST8). En ninguno de estos aislamientos se encontró ACME.

\section{Determinación del posible origen de los aislamientos SASM}

Una posible explicación para la circulación de aislamientos SASM-USA300 en el 2007 puede ser que los aislamientos SARM-USA300 hayan perdido su SCCmec. Varios estudios han reportado que el SCCmec puede escindirse completa o parcialmente, dejando residuos de ADN después del marco orfX y una duplicación del sitio attB $(35,36)$. Para determinar la posible escisión del $\mathrm{SCC} m e c$ en estos aislamientos, se analizó la variabilidad genética del sitio attB y sus alrededores por medio de dos metodologías, IDI-SARM (20) y secuenciación. Los nueve aislamientos SASMUSA300 no contenían residuos de algún tipo de
SCCmec y mostraron un solo sitio attB, lo cual sugiere que estos aislamientos posiblemente no han adquirido un SCCmec. Además, los resultados de la secuenciación también permitieron establecer no sólo que el sitio attB estaba intacto, sino que las regiones aledañas eran idénticas a las reportadas para las cepas USA300, NCTC8325, COL y N315.

\section{Discusión}

El interés por determinar las características genéticas, epidemiológicas y moleculares de los aislamientos SASM se ha incrementado en la última década debido a que el comportamiento genético de poblaciones de los aislamientos SASM tiene un fuerte impacto en la genética de poblaciones de los aislamientos SARM, y hoy ha cobrado mayor importancia frente al cambio epidemiológico mundial que estamos observando en $S$. aureus con la diseminación y recambio 'clonal' de los aislamientos SARM-GC, los cuales han surgido probablemente por la adquisición del SCCmec por parte de aislamientos SASM que circulaban en la comunidad. 
Ahora, el número de cepas SARM-GC se ha incrementado debido a dos factores: una expansión 'clonal' de los linajes SARM-GC y la conversión a SARM-GC de otros linajes SASM-GC que circulan en la comunidad por la adquisición del SCCmec (17). Sin embargo, epidemiológicamente se ha observado que solo unos pocos linajes genéticos SASM tienen la capacidad de adquirir el SCCmec, lo cual ha sido confirmado por experimentos in vitro $(17,37)$. Por esto es importante caracterizar frecuentemente los aislamientos SASM para contar con más herramientas predictivas de los eventuales cambios genéticos de poblaciones que puedan ocurrir en los aislamientos SARM y, así, emitir recomendaciones tempranas para la vigilancia, el tratamiento y la contención de las infecciones causadas por este microorganismo.

En nuestro estudio, 48,9\% de las infecciones se debía a aislamientos SARM, lo cual representa un porcentaje alto comparado con la mayoría de países latinoamericanos (38). Los perfiles de sensibilidad presentaron un comportamiento diferente en los dos tipos de aislamientos, ya que más de 80,0\% de los SARM fue multirresistente (resistencia a tres o más antibióticos) mientras que los SASM presentaron una menor resistencia a antibióticos no betalactámicos (78,7\%); esto se debe a que $80,0 \%$ de los aislamientos SARM presentaba características genéticas y moleculares relacionadas con el clon chileno, el cual es multirresistente (a oxacilina, gentamicina, eritromicina, ciprofloxacina y clindamicina) y ha sido asociado a infecciones hospitalarias en Colombia y Suramérica desde hace varios años $(29,30,39)$.

Los análisis de PFGE demostraron una menor variabilidad genética de los aislamientos SARM respecto a los SASM, como lo han reportado otros autores a nivel mundial (24,26,28,40-42). El análisis de la región J3 de los aislamientos SARM-USA300 nos permitió confirmar que tienen un SCCmec IVc o, como debe reportarse, SCCmec IV.3.1.2.

Otros autores han reportado la identificación de otras variantes del clon USA300: en Dinamarca, Larsen, et al., identificaron un aislamiento SARM con un pulsotipo de PFGE idéntico a USA300, pero sin los genes lukS-PV/lukF-PV, y con un tipo de spa t024 y ACME insertado corriente arriba del $\mathrm{SCCmec}(6,43)$. El origen genético y evolutivo de estas variantes aún se desconoce.

Se pueden plantear tres hipótesis para explicar la diseminación de la variante USA300 en Colombia: una, por la diseminación de un aislamiento SARM relacionado con el clon USA300-IV.1.1.1, el cual perdió su SCCmec IV.1.1.1 y adquirió un SCCmec IV.3.1.2, pero aunque esta situación puede darse, no existe ninguna evidencia experimental que la sustente. La segunda posibilidad es la diseminación desde Norteamérica de un aislamiento relacionado con el clon USA300, pero con un SCCmec IV.3.1.2. A pesar de que no existen muchos reportes sobre esto, en el 2007, Goering, et al., reportaron un aislamiento USA300 con este SCCmec (44), aunque no se definió exactamente si era IV.3.1.1 o IV.3.1.2. Finalmente, la tercera posibilidad es la diseminación de aislamientos SASM con un componente genético similar al clon USA300, pero que adquirieron un $\mathrm{SCC} m e c$ diferente en nuestro país.

Nuestros resultados respaldan con mayor fuerza esta última hipótesis, pues se detectaron nueve aislamientos SASM causantes de infecciones invasivas con pulsotipos relacionados con el clon USA300 ( $>84 \%$ de similitud), con tipos de spa idénticos (t008) o relacionados (t024), con factores genéticos transportados en elementos genéticos móviles identificados en este clon como los genes sek y seq de la isla de capacidad patógena 5, así como el gen bsaB de la isla genómica $\beta$ y los genes lukS-PV/lukF-PV del profago 2. El análisis del sitio attB no mostró duplicación de secuencias, lo cual sugiere que estos SASM-USA300 encontrados en Colombia no provinieron de aislamientos SARMUSA300 que hubieran perdido su SCCmec.

Noto, et al., analizaron la secuencia del sitio attB y sus regiones aledañas en 42 aislamientos SASM de diferentes linajes genéticos y encontraron una amplia variabilidad genética en las secuencias que rodean este sitio, pero, además, encontraron que los aislamientos que tenían la misma secuencia presente en los aislamientos SARM USA300, NCTC8325, COL y N315 tenían mayor capacidad de insertar el SCCmec por integración específica al sitio (17).

Ahora bien, el análisis de las regiones aledañas a este sitio attB mostró que los aislamientos SASMUSA300 identificados en este estudio tenían las mismas secuencias de los aislamientos SARM. Estos resultados sugieren que los aislamientos SASM-USA300 tienen la capacidad de insertar el SCCmec, por lo cual podrían ser un reservorio de nuevos aislamientos SARM. Además, existen varios reportes sobre la diseminación de aislamientos SASM relacionados con el clon USA300 en Estados Unidos. Mishaan, et al., reportaron que entre el 2000 y el 2002, $25 \%$ de las infecciones por SASM 
en niños fueron ocasionadas por aislamientos relacionados con el clon USA300 (27). Highlander, et al., secuenciaron y publicaron el genoma de un aislamiento SASM USA300, el cual, además de la ausencia del SCCmec, presentaba pocas variaciones genéticas con respecto a los clones SARM USA300 FPR3757 y USA300-HOU (28).

La hipótesis que se plantea con base en nuestros resultados es que el posible origen de la variante SARM-USA300 en nuestra región fue la diseminación de aislamientos SASM relacionados genéticamente con el clon USA300, los cuales adquirieron el SCCmec IV.3.1.2 por un evento genético posterior. Por otro lado, el surgimiento de estos aislamientos SASM relacionados con USA300 y con potencial para integrar el SCCmec genera preocupación, ya que dichos aislamientos también son patógenos y pueden continuar diseminándose y adquirir diferentes tipos de casete $\mathrm{SCCmec}$, aumentando así la expansión 'clonal' de aislamientos SARM-GC y, por tanto, las infecciones en la comunidad, en donde aún no existe una vigilancia activa en nuestro país.

La diseminación de aislamientos SASM-USA300 y su probable capacidad de adquirir SCCmec puede estar contribuyendo al aumento de la frecuencia de infecciones causadas por el clon SARM-USA300, reportado en nuestro país en el 2006 y que ya es causante de aproximadamente 94 y $60 \%$ de las infecciones en población pediátrica y de adultos, respectivamente $(8,10,45,46$; Álvarez M, Escobar J, Márquez A, Castro B, Mujica S, Leal A, Bonilla C, et al. Clonal replacement with MRSA Staphylococcus aureus USA300-related clone among infected children in Colombia [Abstract C2-074]. 51 ${ }^{\text {st }}$ Interscience Conference on Antimicrobial Agents and Chemotherapy; 2011; Chicago: September 17 to 20, 2011: American Society for Microbiology).

Es necesario seguir el estudio de este fenómeno y profundizar en el posible origen de nuestros aislamientos SARM para llevar a cabo la vigilancia epidemiológica y los estudios clínicos no solo de los SARM sino de los SASM, pues en muchas ocasiones se subestiman debido a que su tratamiento antibiótico es mucho más fácil y efectivo, pero podrían ser el reservorio de aislamientos más patógenos y virulentos como se ha descrito con relación al USA300.

\section{Agradecimientos}

A Liliana Isabel Barrero, David Guío, Nicolás Hernández y Santiago Correa por su valioso apoyo en la realización de este trabajo y al Hospital Universitario Mayor Méderi (antiguamente Hospital San Pedro Claver) por el envío de las muestras.

\section{Conflicto de intereses}

Los autores manifiestan no tener conflicto de intereses que ocasionen algún sesgo en el manejo e interpretación de la información proporcionada en este estudio.

\section{Financiación}

Este trabajo fue financiado por el Departamento Administrativo de Ciencia, Tecnología e InnovaciónColciencias, mediante el proyecto "Estandarización de una herramienta molecular para la diferenciación entre aislamientos de Staphylococcus aureus resistentes a meticilina adquiridos en comunidad (SARM-AC) y adquiridos en el hospital (SARMAH)", código 1308-49326155, y por la División de Investigaciones de la Universidad El Bosque.

\section{Referencias}

1. Gordon RJ, Lowy FD. Pathogenesis of methicillinresistant Staphylococcus aureus infection. Clin Infect Dis. 2008;46(Suppl.5):S350-9. http://dx.doi.org/10.1086/533591

2. Deurenberg RH, Stobberingh EE. The evolution of Staphylococcus aureus. Infect Genet Evol. 2008;8:747-63. http://dx.doi.org/10.1016/j.meegid.2008.07.007

3. Diep BA, Gill SR, Chang RF, Phan TH, Chen JH, Davidson MG, et al. Complete genome sequence of USA300, an epidemic clone of community-acquired meticillin-resistant Staphylococcus aureus. Lancet. 2006;367:731-9. http:// dx.doi.org/10.1016/S0140-6736(06)68231-7

4. Tenover FC, Goering RV. Methicillin-resistant Staphylococcus aureus strain USA300: Origin and epidemiology. J Antimicrob Chemother. 2009;64:441-6. http://dx.doi.org/10.1093/jac/dkp241

5. Pan ES, Diep BA, Carleton HA, Charlebois ED, Sensabaugh GF, Haller BL, et al. Increasing prevalence of methicillin-resistant Staphylococcus aureus infection in California jails. Clin Infect Dis. 2003;37:1384-8. http://dx.doi. org/10.1086/379019

6. Larsen A, Stegger M, Goering R, Sorum M, Skov R. Emergence and dissemination of the methicillin resistant Staphylococcus aureus USA300 clone in Denmark (20002005). Euro Surveill. 2007;12:22-24.

7. Tietz A, Frei R, Widmer AF. Transatlantic spread of the USA300 clone of MRSA. N Engl J Med. 2005;353:532-3.

8. Álvarez-Olmos MI, Enríquez SP, Pérez-Roth E, MéndezÁlvarez S, Escobar J, Vanegas $\mathrm{N}$, et al. Pediatric cases from Colombia caused by a Panton-Valentine Leukocidin-positive community-acquired methicillin-resistant Staphylococcus aureus ST8-SCCmecIVc clone. Pediatr Infect Dis J. 2009;28:935. http://dx.doi.org/10.1056/NEJ M200508043530522

9. Reyes J, Rincón S, Díaz L, Panesso D, Contreras GA, Zurita J, et al. Dissemination of methicillin-resistant Staphylococcus aureus USA300 sequence type 8 lineage in 
Latin America. Clin Infect Dis. 2009;49:1861-7. http://dx.doi. org/10.1086/648426

10. Álvarez CA, Yomayusa N, Leal AL, Moreno J, MéndezÁlvarez S, Ibáñez M, et al. Nosocomial infections caused by community-associated methicillin-resistant Staphylococcus aureus in Colombia. Am J Infect Control. 2010;38:315-8. http://dx.doi.org/10.1016/j.ajic.2009.05.013

11. Jiménez JN, Ocampo AM, Vanegas JM, Rodríguez EA, Mediavilla JR, Chen L, et al. CC8 MRSA strains harboring SCCmec type IVc are predominant in Colombian hospitals. PLoS One. 2012;7:e38576. http://dx.doi.org/10.1371/journal. pone. 0038576

12. Martineau F, Picard FJ, Lansac N, Menard C, Roy PH, Ouellette $\mathbf{M}$, et al. Correlation between the resistance genotype determined by multiplex PCR assays and the antibiotic susceptibility patterns of Staphylococcus aureus and Staphylococcus epidermidis. Antimicrob Agents Chemother. 2000;44:231-8. http://dx.doi.org/10.1128/AAC. 44.2.231-238.2000

13. Clinical and Laboratory Standards Institute. Performance Standards for Antimicrobial Susceptibility Testing; Twentysecond Informational Supplement: CLSI document M100-S23. Wayne, PA: Clinical and Laboratory Standar Institute; 2013.

14. Oliveira DC, de Lencastre H. Multiplex PCR strategy for rapid identification of structural types and variants of the mec element in methicillin-resistant Staphylococcus aureus. Antimicrob Agents Chemother. 2002;46:2155-61. http://dx. doi.org/10.1128/AAC.46.7.2155-2161.2002

15. Milheirico C, Oliveira DC, de Lencastre H. Multiplex PCR strategy for subtyping the staphylococcal cassette chromosome mec type IV in methicillin-resistant Staphylococcus aureus: 'SCCmec IV multiplex'. J Antimicrob Chemother. 2007;60:42-8. http://dx.doi.org 10.1093/jac/dkm112

16. Milheirico $\mathbf{C}$, Oliveira DC, de Lencastre $\mathbf{H}$. Update to the multiplex PCR strategy for assignment of mec element types in Staphylococcus aureus. Antimicrob Agents Chemother. 2007;51:3374-7. http://dx.doi.org/10.1128/AAC.00275-07

17. Noto MJ, Kreiswirth BN, Monk AB, Archer GL. Gene acquisition at the insertion site for SCCmec, the genomic island conferring methicillin resistance in Staphylococcus aureus. J Bacteriol. 2008;190:1276-83. http://dx.doi.org/10. 1128/JB.01128-07

18. Harmsen D, Claus H, Witte W, Rothganger J, Turnwald D, Vogel U. Typing of methicillin-resistant Staphylococcus aureus in a university hospital setting by using novel software for spa repeat determination and database management. $J$ Clin Microbiol. 2003;41:5442-8. http://dx.doi.org/10.1128/ JCM.41.12.5442-5448.2003

19. Gilot P, Lina G, Cochard T, Poutrel B. Analysis of the genetic variability of genes encoding the RNA IIIactivating components Agr and TRAP in a population of Staphylococcus aureus strains isolated from cows with mastitis. J Clin Microbiol. 2002;40:4060-7. http://dx.doi. org/10.1128/JCM.40.11.4060-4067.2002

20. Huletsky A, Giroux R, Rossbach V, Gagnon $M$, Vaillancourt M, Bernier M, et al. New real-time PCR assay for rapid detection of methicillin-resistant Staphylococcus aureus directly from specimens containing a mixture of staphylococci. J Clin Microbiol. 2004;42:1875-84. http://dx. doi.org/10.1128/JCM.42.5.1875-1884.2004
21. Lina G, Piemont Y, Godail-Gamot F, Bes M, Peter MO, Gauduchon V, et al. Involvement of Panton-Valentine leukocidin-producing Staphylococcus aureus in primary skin infections and pneumonia. Clin Infect Dis. 1999;29:1128-32. http://dx.doi.org/10.1086/313461

22. Chung $M$, de Lencastre $H$, Matthews $P$, Tomasz $A$, Adamsson I, Aires de Sousa M, et al. Molecular typing of methicillin-resistant Staphylococcus aureus by pulsedfield gel electrophoresis: Comparison of results obtained in a multilaboratory effort using identical protocols and MRSA strains. Microb Drug Resist. 2000;6:189-98. http://dx.doi. org/10.1089/mdr.2000.6.189

23. Tenover FC, Arbeit RD, Goering RV, Mickelsen PA, Murray BE, Persing DH, et al. Interpreting chromosomal DNA restriction patterns produced by pulsed-field gel electrophoresis: Criteria for bacterial strain typing. J Clin Microbiol. 1995;33:2233-9.

24. Enright MC, Day NP, Davies CE, Peacock SJ, Spratt BG. Multilocus sequence typing for characterization of methicillin-resistant and methicillin-susceptible clones of Staphylococcus aureus. J Clin Microbiol. 2000;38:1008-15.

25. Escobar JA, Gómez IT, Murillo MJ, Castro BE, Chavarro B, Márquez RA, et al. Design of two molecular methodologies for the rapid identification of Colombian community-acquired methicillin-resistant Staphylococcus aureus isolates. Biomedica. 2012;32:214-23. http://dx.doi. org/10.7705/biomedica.v32i2.645

26. David MZ, Boyle-Vavra S, Zychowski DL, Daum RS. Methicillin-susceptible Staphylococcus aureus as a predominantly healthcare-associated pathogen: A possible reversal of roles? PLoS One. 2011;6:e18217. http://dx.doi. org/10.1371/journal.pone.0018217

27. Mishaan AM, Mason EO Jr., Martínez-Aguilar G, Hammerman W, Propst JJ, Lupski JR, et al. Emergence of a predominant clone of community-acquired Staphylococcus aureus among children in Houston, Texas. Pediatr Infect Dis J. 2005;24:201-6.

28. Highlander SK, Hulten KG, Qin X, Jiang H, Yerrapragada $\mathrm{S}$, Mason EO Jr., et al. Subtle genetic changes enhance virulence of methicillin resistant and sensitive Staphylococcus aureus. BMC Microbiol. 2007;7:99. http://dx.doi. org/10.1186/1471-2180-7-99

29. Rodríguez-Noriega E, Seas C, Guzmán-Blanco M, Mejía C, Álvarez C, Bavestrello L, et al. Evolution of methicillinresistant Staphylococcus aureus clones in Latin America. Int J Infect Dis. 2010;14:e560-6. http://dx.doi.org/10.1016/j. ijid.2009.08.018

30. Mayor L, Ortellado J, Menacho C, Lird G, Courtier C, Gardon C, et al. Molecular characterization of methicillinresistant Staphylococcus aureus isolates collected in Asuncion, Paraguay. J Clin Microbiol. 2007;45:2298-300. http://dx.doi.org/10.1128/JCM.00040-07

31. Becker AP, Santos O, Castrucci FM, Dias C, D'Azevedo PA. First report of methicillin-resistant Staphylococcus aureus Cordobes/Chilean clone involved in nosocomial infections in Brazil. Epidemiol Infect. 2012;140:1372-5. http://dx.doi.org/10.1017/S095026881100210X

32. IWG-SCC. Classification of staphylococcal cassette chromosome mec (SCCmec): Guidelines for reporting novel SCCmec elements. Antimicrob Agents Chemother. 2009;53: 4961-7. http://dx.doi.org/10.1128/AAC.00579-09. 
33. Ma XX, Galiana A, Pedreira W, Mowszowicz M, Christophersen I, Machiavello S, et al. Communityacquired methicillin-resistant Staphylococcus aureus, Uruguay. Emerg Infect Dis. 2005;11:973-6. http://dx.doi.org/10.3201/ eid1106.041059

34. Argudin MA, Mendoza MC, Rodicio MR. Food poisoning and Staphylococcus aureus enterotoxins. Toxins (Basel). 2010;2:1751-73. http://dx.doi.org/10.3390/toxins2071751.

35. Donnio PY, Oliveira DC, Faria NA, Wilhelm N, Le Coustumier A, de Lencastre $\mathbf{H}$. Partial excision of the chromosomal cassette containing the methicillin resistance determinant results in methicillin-susceptible Staphylococcus aureus. J Clin Microbiol. 2005;43:4191-3. http://dx.doi.org/10. 1128/JCM.43.8.4191-4193.2005

36. Donnio PY, Louvet L, Preney L, Nicolas D, Avril JL, Desbordes L. Nine-year surveillance of methicillin-resistant Staphylococcus aureus in a hospital suggests instability of mecA DNA region in an epidemic strain. J Clin Microbiol. 2002;40:1048-52. http://dx.doi.org/10.1128/JCM.40.3.10481052.2002

37. Enright MC, Robinson DA, Randle G, Feil EJ, Grundmann H, Spratt BG. The evolutionary history of methicillinresistant Staphylococcus aureus (MRSA). Proc Natl Acad Sci USA. 2002;99:7687-92. http://dx.doi.org/10.1073/pnas. 122108599

38. Guzmán-Blanco $\mathbf{M}$, Mejía $\mathrm{C}$, Isturiz R, Álvarez $\mathbf{C}$, Bavestrello L, Gotuzzo E, et al. Epidemiology of methicillinresistant Staphylococcus aureus (MRSA) in Latin America. Int J Antimicrob Agents. 2009;34:304-8. http://dx.doi.org/10. 1016/j.jantimicag.2009.06.005

39. Cruz C, Moreno J, Renzoni A, Hidalgo M, Reyes $\mathrm{J}$, Schrenzel $\mathrm{J}$, et al. Tracking methicillin-resistant Staphylococcus aureus clones in Colombian hospitals over 7 years (1996-2003): Emergence of a new dominant clone. Int J Antimicrob Agents. 2005;26:457-62. http://dx.doi. org/10. 1016/j.ijantimicag.2005.08.013
40. Chambers HF, Deleo FR. Waves of resistance: Staphylococcus aureus in the antibiotic era. Nat Rev Microbiol. 2009;7:629-41. http://dx.doi.org/10.1038/nrmicro2200.

41. Branger C, Gardye C, Galdbart JO, Deschamps C, Lambert N. Genetic relationship between methicillin-sensitive and methicillin-resistant Staphylococcus aureus strains from France and from international sources: Delineation of genomic groups. J Clin Microbiol. 2003;41:2946-51. http:// dx.doi.org/10.1128/JCM.41.7.2946-2951.2003

42. Strommenger B, Kettlitz C, Weniger T, Harmsen D, Friedrich AW, Witte W. Assignment of Staphylococcus isolates to groups by spa typing, Smal macrorestriction analysis, and multilocus sequence typing. J Clin Microbiol. 2006;44:2533-40. http://dx.doi.org/10.1128/JCM.00420-06

43. Bartels MD, Hansen LH, Boye K, Sorensen SJ, Westh $\mathrm{H}$. An unexpected location of the arginine catabolic mobile element (ACME) in a USA300-related MRSA strain. PLoS One. 2011;6:e16193. http://dx.doi.org/10.1371/journal.pone. 0016193

44. Goering RV, McDougal LK, Fosheim GE, Bonnstetter KK, Wolter DJ, Tenover FC. Epidemiologic distribution of the arginine catabolic mobile element among selected methicillinresistant and methicillin-susceptible Staphylococcus aureus isolates. J Clin Microbiol. 2007;45:1981-4. http://dx.doi. org/10.1128/JCM.00273-07

45. Escobar JA, Márquez-Ortíz RA, Álvarez-Olmos MI, Leal AL, Castro BE, Vanegas N. Detection of a new community genotype methicillin-resistant Staphylococcus aureus clone that is unrelated to the USA300 clone and that causes pediatric infections in Colombia. J Clin Microbiol. 2013;51:661-4. http://dx.doi.org/10.1128/JCM.01299-12

46. Olarte NM, Valderrama IA, Reyes KR, Garzón MI, Escobar JA, Castro BE, et al. Methicillin-resistant Staphylococcus aureus colonization in a Colombian hospital intensive care unit: Phenotypic and molecular characterization. Biomedica. 2010;30:353-61. http://dx.doi.org/10.7705/biomedica.v30i3.269 